\title{
Utilisation of poultry management information in three rural districts of Tanzania
}

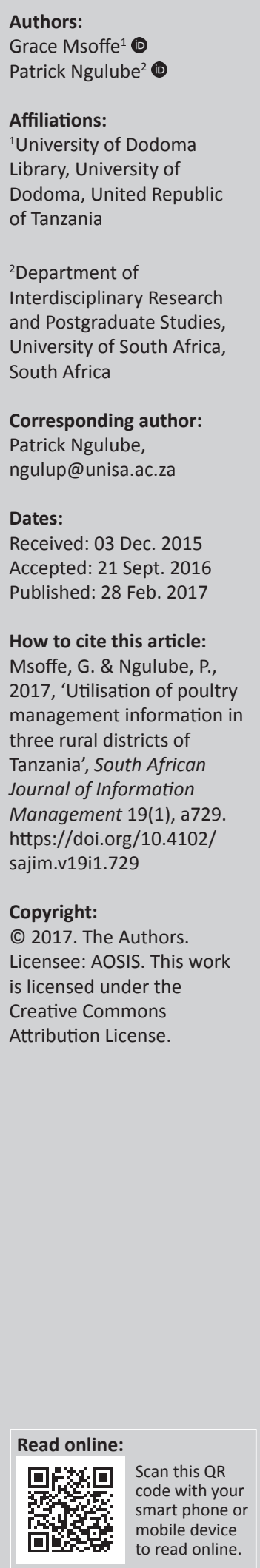

Background: In Tanzania, poultry farming plays an important role in improving rural livelihoods and contributes to the national economy. Promoting utilisation of poultry management information can support farmers in making good decisions and translate into efficiency in poultry production.

Objective: Being part of a $\mathrm{PhD}$ project, this study assessed the utilisation of poultry management information among farmers in three rural districts of Tanzania. The objective was to establish the extent of information use, types of information used, the constraints faced by farmers in using information and the strategies used by information providers to ensure farmers use the information.

Method: Quantitative and qualitative data were collected using questionnaires, focus group discussions and interviews. Quantitative data were analysed using the SPSS ${ }^{\odot}$ software, and the meaning of qualitative data was established using content analysis.

Results: The findings revealed that most of the farmers used poultry management information. Information on disease control, poultry protection and markets was the most used. Information on poultry production and hatching were the least used. Poultry farmers faced various challenges in the course of using poultry management information. Most of the challenges were linked to poverty, ignorance and limited literacy.

Conclusion: The study concludes that farmers in the surveyed communities had limited skills on utilising information. The findings necessitate a need for information providers to ensure that farmers are well informed of the benefits of utilising information. It is recommended that imparting skills for information use be considered as part of information provision in rural communities, as it would facilitate use of information.

\section{Introduction}

Information use is often linked to information need, as information is needed so that it can be used (Meho \& Hass 2001). It is mainly concerned with what happens with the information after it has been acquired, and how it is applied to accomplishing a specific goal and/or solving a particular problem (Bartlett \& Toms 2005). An informed person is able to make better decisions in accomplishing a certain task or solving a problem and accruing the benefits associated with information use (Potnis 2014).

Improvement in agricultural production requires utilisation of agricultural information (Olaniyi \& Adewale 2011). The use of agricultural information enhances farming productivity by assisting farmers to make proper decisions regarding their farming activities (Bachhav 2012). Similarly, a community that recognises and uses information has a greater chance for development (Kamba 2009). Thus, it is important for the poultry farmers to utilise information with the purpose of improving poultry production for the benefit of farmers, communities and the nation at large. Poultry farmers need a wide variety of information to increase their knowledge on poultry management (Temba et al. 2016). The use of poultry management information helps to increase poultry production, which translates into the improvement of farmers' standard of living and the national economy.

Poultry production is an important sector of Tanzania's economy (Temba et al. 2016). At the turn of the century, the poultry industry in Tanzania was estimated to be 40.5 billion Tanzania shillings, worth USD 50.6 million (Minga et al. 2000). It contributes about 3\% of the agricultural GDP and $1 \%$ of national domestic product (FAO 2011). It comprises commercial poultry production and traditional poultry production. Commercial poultry production is more prominent in urban and peri-urban areas. Traditional poultry production is mostly practised in rural areas, 
contributing about $70 \%$ of the flock, and $100 \%$ of poultry meat and eggs consumed in rural areas and 20\% in urban areas (Boki 2000; United Republic of Tanzania 2006). Traditional poultry production is an important farming activity in the rural areas because it can be afforded by the poor rural farmers (Guèye 2000). Poultry production is an important source of income for most of the rural poor households and plays an essential role in improving household income and alleviating poverty (Knueppel et al. 2009, 2010). This is because of an increasing urban demand for traditionally kept poultry, which is stimulating trade from rural areas to urban areas and creating opportunities for rural farmers to sell more poultry at a better price (Msoffe 2015). It is an important source of protein-rich food acting as an effective way to reduce food insecurity and malnutrition in the rural areas (Knueppel et al. 2009).

Despite the importance of the traditional poultry production for economic development, there has been low poultry production in rural Tanzania. The use of poultry management information among farmers will always lead to increased poultry productivity (Ofuoku, Emah \& Itedjere 2008). The low poultry production implies that poultry management information is not adequately utilised by farmers. Thus, it is important to investigate the information utilisation in the rural areas of Tanzania. The study assessed the extent of information use, types of information used, the constraints faced by farmers in using information and the strategies used by information providers to ensure farmers use the information. The findings could be useful in taking measures to ensure information that reaches the rural farmers is effectively utilised.

\section{Methodology}

This study used a quantitative approach to large extent. A survey research strategy was used, and it was supplemented by methodological triangulation with the intention that the methods will converge to support the objectives of the study (Leedy \& Ormrod 2005:99). Using a purposive sampling technique, three rural districts in Tanzania were selected to include those that were involved in the poultry management programmes; and from each of the selected districts, one ward with higher poultry production was selected. From each of the selected wards, three villages with well-established poultry production were selected. The districts selected for the study were Iringa rural, Morogoro rural and Mvomero. The villages involved in the study included Fulwe, Mikese and Mkambarani in Morogoro rural; Mafuluto, Malinzanga and Nyamahana in Iringa rural; and Changarawe, Tangeni and Vikenge in Mvomero. Simple random sampling technique was used to select farmers. A total of 360 farmers participated in questionnaire survey.

The purposive sampling technique was used to select individuals for focus group discussions (FGDs) and interviews. A sample of 160 farmers was purposively drawn from the participants of questionnaire survey to take part in FGDs. Sixteen FGDs were held. The typical case sampling technique was used to select information providers (extension officers, researchers, local leaders). Twenty-two information providers participated in the interviews.

The triangulation of data collection instruments facilitated the collection of reliable data. Multiple research instruments were used to cross-check and verify the reliability of research tools and the validity of the collected data (McNeil \& Chapman 2005). The use of FGDs and interviews facilitated face-to-face communication between the first author and participants, which enabled the first author to explain questions, depending on the level of understanding of the participants. Likewise, questionnaires were administered during face-to-face interaction between the first author and respondents. Furthermore, FGDs were used to validate information collected by means of the questionnaire. Similarly, data from interviews with information providers were used to clarify the different findings from the questionnaire administered to farmers.

Quantitative and qualitative data were collected through questionnaires, FGDs and interviews. The FGDs and interviews were used to supplement data gained through questionnaires. The quantitative data were collected through close-ended questions in questionnaires. Qualitative data were collected through FGDs, interviews and open-ended questions in questionnaires. Quantitative data were analysed using SPSS $^{\circledR}$, and qualitative data were analysed using content analysis as suggested by Ngulube (2015). Quantitative data analysis involved descriptive and inferential numeric analysis, while qualitative data analysis involved description and thematic text analysis. Frequencies, percentages and forms of graphic presentation and narrative descriptions were used for data presentation. The study was guided by the following research questions:

- Do farmers use the poultry management information that they access?

- What types of poultry management information are used by farmers?

- What are the factors hindering farmers from using poultry management information?

- What are the strategies used by information providers in ensuring that farmers use information?

\section{Findings and discussions}

Starting with a discussion of the characteristics of the poultry farmers and information providers who participated in the study, this section discusses the findings based on the four research questions that informed the study.

\section{Characteristics of poultry farmers}

A total of 360 poultry farmers participated in the survey questionnaire. The mean age of the respondents was 39 years, 
TABLE 1: Characteristics of poultry farmers $(N=360)$.

\begin{tabular}{|c|c|c|c|}
\hline Variable & Categories & Frequency $(N)$ & $\%$ \\
\hline \multirow[t]{2}{*}{ Gender } & Men & 189 & 52.5 \\
\hline & Women & 171 & 47.5 \\
\hline \multirow[t]{4}{*}{ Age (years) } & Below 18 & 2 & 0.6 \\
\hline & $18-37$ & 173 & 48.1 \\
\hline & $38-57$ & 130 & 36.1 \\
\hline & 58 and above & 55 & 15.2 \\
\hline \multirow[t]{4}{*}{ Educational levels $\dagger$} & $\begin{array}{l}\text { Post-secondary } \\
\text { education }\end{array}$ & 4 & 1.1 \\
\hline & Secondary education & 22 & 6.1 \\
\hline & Primary education & 287 & 79.7 \\
\hline & Informal education & 4 & 1.1 \\
\hline \multirow[t]{3}{*}{ Occupation } & $\begin{array}{l}\text { Crop farming and } \\
\text { livestock keeping }\end{array}$ & 341 & 94.7 \\
\hline & $\begin{array}{l}\text { Livestock keeping and } \\
\text { small business }\end{array}$ & 13 & 3.6 \\
\hline & $\begin{array}{l}\text { Livestock keeping and } \\
\text { skilled work }\end{array}$ & 6 & 1.7 \\
\hline
\end{tabular}

$\dagger$, Forty-three respondents were illiterate.

where the majority $(303,84.1 \%)$ were aged between 18 and 57 years (Table 1). Most of the respondents had primary education, few had secondary education, whereas 43 (11.9\%) were illiterate. Men dominated the formal education category. Respondents with primary education comprised 131 (36.4\%) women and $156(43.3 \%)$ men, while those with secondary education comprised $9(2.5 \%)$ women and 13 (3.6\%) men. The majority of the respondents were involved in mixed farming (crop farming and livestock keeping). Some farmers were involved in livestock keeping and small businesses, while few farmers did livestock keeping and skilled work (See Table 1).

\section{Characteristics of information providers}

Twenty-two information providers participated in the semistructured interviews. The mean age of the respondents was 42 years. The majority of the respondents were between 35 and 55 years, and few respondents were above 55 years. They comprised village executive officers, researchers, district agricultural officers, extension officers and a ward executive officer (See Table 2).

\section{Use of poultry management information}

The findings revealed that majority of the respondents (332, $92.2 \%$ ) accessed poultry management information. Out of those who accessed information, more than half $(187,56.3 \%$, $n=332)$ used the poultry management information they acquired. Most of the respondents $(146,78.1 \%, n=187$ ) indicated that the information assisted them to solve the problems and provide better management of their poultry. Some respondents $(41,21.9 \%, n=187)$ indicated that the information was not helpful in solving their problems. The findings demonstrate that accessing information does not guarantee that the information will be utilised for solving the problems and improving poultry production. Coudel and Tonneau (2010:63) emphasised that 'information may
TABLE 2: Characteristics of information providers $(N=22)$.

\begin{tabular}{lll}
\hline Variables & Frequency $(N)$ & $\%$ \\
\hline Gender & 15 & 68.2 \\
Men & 7 & 31.8 \\
Women & & \\
Age & 18 & 81.8 \\
$35-55$ years & 4 & 18.2 \\
$\quad$ Above 55 years & & \\
Educational levels & 6 & 27.3 \\
Degree & 6 & 27.3 \\
Secondary education & 4 & 18.2 \\
Tertiary certificate & 3 & 13.6 \\
Diploma & 3 & 13.6 \\
Primary education & & \\
Job & 9 & 40.9 \\
$\quad$ Village executive officers & 6 & 27.3 \\
Researchers & 3 & 13.6 \\
District agricultural officers & 3 & 13.6 \\
Extension officers & 1 & 4.5 \\
Ward executive officer & & \\
\hline
\end{tabular}

TABLE 3: Information use by education categories $(N=187)$.

\begin{tabular}{lll}
\hline Educational levels & Frequency $(\boldsymbol{N})$ & $\mathbf{\%}$ \\
\hline Post-secondary education & 4 & 2.1 \\
Secondary education & 22 & 11.8 \\
Primary education & 159 & 85 \\
Informal education & 1 & 0.5 \\
Illiterate & 1 & 0.5 \\
\hline
\end{tabular}

seem appropriate, usable, relevant, but it can only be useful if the actors have the capacity to use it and if their environment offers them the opportunity to use it'. This calls for information providers to devise follow-up strategies to ensure that farmers are able to use the information they access.

The optimal use of information can be realised if information is disseminated in the formats that are desirable by the target audience. This may be achieved with full participation of all stakeholders such as rural farmers, researchers and various information providers (Kalusopa 2005). In order for users to access and use information, they must have economic resources, skills, technology and social resources (Heeks 2005). It is therefore important to take into consideration all the factors influencing the use of poultry management information in rural areas. Regular follow-ups may shed light on what changes need to be applied in order for the information to be useful; this may entail changing the format or the delivery method.

Table 3 illustrates the information use by education categories. The findings suggest that farmers' educational levels have an influence on the utilisation of poultry management information. There was a variation in the use of information across different education categories. Farmers with primary education and secondary education were the majority among those who utilised information, in comparison to illiterate farmers and those who had informal education. All the farmers with secondary and post-secondary education used the information (See Table 3). On the other hand, 
more men $(101,54 \%)$ utilised information compared to women $(86,46 \%)$. As the demographic characteristics show that men dominated the formal education categories, it is imperative to attribute their use of information with their level of education.

These findings are inconsistent with those of Olaniyi and Adewale (2012), who reported that there was no relationship between educational level and level of utilisation of agricultural information. The difference may be attributed to the fact that the respondents in the study of Olaniyi and Adewale (2012) were rural youth, while this study dealt with all age categories. Thus, educational levels in this study may seem to be important, particularly because of the disparity in terms of level of understanding. It is probable that youth educational levels did not have significant differences as far as understanding and using agricultural information are concerned.

Farmers' ability to access and use information is highly dependent on educational level (Eze et al. 2006; Fawole 2006; Waller et al. 1998). This implies that inadequate knowledge to use the information is directly related to the educational levels of farmers. This is consistent with Ofuoku et al. (2008), who assert that the higher level of formal education has a positive influence on farmers' use of information.

Most of the farmers in rural areas of Tanzania had little education as shown in their demographic characteristics (Table 1). With low level of education, it is not guaranteed that the farmers would have the ability to access and use information disseminated in various formats. This partly explains the low poultry productivity in the rural areas. The situation is directly related to the inadequate use of information caused by limited educational levels of the majority of rural farmers in Tanzania. It is therefore crucial for information dissemination services to take into consideration the farmers' literacy level to enable effective utilisation of information.

\section{Types of information used by poultry farmers}

The findings (Figure 1) established that information on poultry disease control was the most used $-187(100 \%, n=187)$. Other types of information that were highly used were information on poultry protection and markets. The least used information was information on poultry production and hatching. Figure 1 presents the detailed findings on the types of poultry management information used by farmers in the surveyed communities.

The findings from FGDs indicated that there was low use of information on poultry feeding and nutrition and information on poultry housing and shelter. Most farmers used information on poultry disease control and were not willing to provide proper feeds and housing for the poultry. Also, some farmers especially in Mafuluto village were not interested in using conventional methods for prevention of poultry diseases because they had experienced massive loss of their poultry when vaccines were used previously. Thus, they were reluctant to use

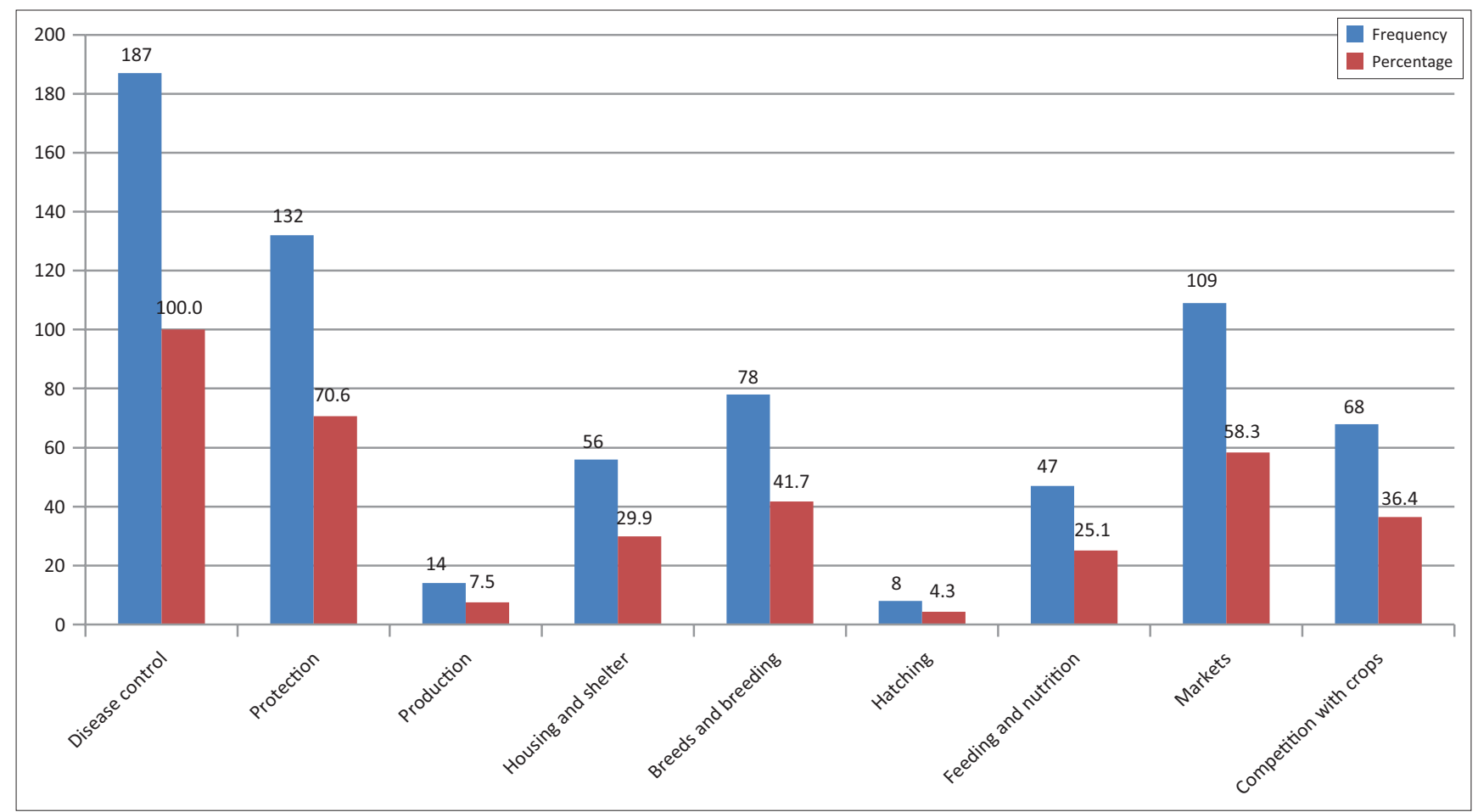

Note: Multiple responses were possible.

FIGURE 1: Types of information used by poultry farmers $(N=187)$. 
any information they received from the extension officer. Some of the typical responses were:

'We have used vaccines previously, and as a result all the poultry died because of Newcastle disease. Now, we only want to use the traditional methods to prevent loss of poultry.' [Female, 50 years old, primary education level]

'Implementing some of the advices from extension officers is expensive, and some of us cannot afford. For instance building a house for the poultry is expensive.' [Male, 55 years old, illiterate]

'It is expensive to get food for the poultry, why should I feed them while they can easily find their own food?' [Female, 43 years old, primary education level]

It was evident from the findings that farmers mainly applied information that had direct impacts on their farming activities. The most used information was the one that directly affected the poultry health and production. For instance, information on diseases that caused death of poultry, information on poultry protection which was crucial for poultry safety and information on poultry markets which was necessary for selling poultry products. These findings agree with that of Byamugisha, Ikoja-Odongo and Nasinyama (2010) who found that farmers mainly used information on controlling animal diseases (51.5\%) and controlling crop diseases $(48.2 \%)$. This implies that information use indicates information needs of poultry farmers and the value poultry farmers attached to particular information.

On the other hand, other types of information were rarely used by farmers. These findings suggest that farmers chose certain information to be more important than the others and utilised those which they considered to be important. For instance, traditionally farmers have been rearing poultry leaving them to find food for themselves. Thus, information on feeding and nutrition would not be taken as an important practice especially if it requires money to buy the feed. In such a situation, it takes a knowledgeable farmer who understands the importance of utilising such information to pay for the recommended inputs. The implication is that poultry farmers need more education and training to make them understand the importance of various farming practices. This calls for the information providers to devise strategies to ensure that farmers understand the benefits of utilising the information.

The findings also demonstrate that the cost associated with utilising information was considered to be an important reason for the failure to use information. Some of the farmers were constrained by the cost of inputs needed to utilise the information. According to Opara (2010), the income level of farmers is very important in facilitating agricultural information use. Opara (2010) emphasises that farmers with a better income are more likely to spend money on looking for information, utilising it and buying the required inputs. An increase in level of utilisation of agricultural information leads to improved productivity (Olaniyi \& Adewale 2012), which in turn leads to improved income (Lwoga et al. 2011). With improved income, the farmer will be able to spend more money on the utilisation of agricultural information, which will further increase agricultural productivity and income. However, most farmers in rural areas of Tanzania had very little income. Thus, the majority of rural farmers could not afford to pay the cost of accessing information and buying the inputs needed to utilise the information. Even when the information was provided free of charge, they could rarely afford to buy the required inputs.

\section{Strategies used by information providers to ensure utilisation of information}

The majority of the information providers $(17,77.3 \%, n=22)$ indicated that they had no strategies for ensuring that farmers used the information. Few information providers $(5,22.7 \%)$ pointed out that they had strategies. The strategies they used (Table 4) were: following up the farmers, practising together with farmers, demonstrating during the seminars and requesting for feedback from farmers. A researcher in Mvomero district organised school children and built a poultry house at their school. He supplied the building materials and bought the poultry and feeds for starting the project. This was a strategy to encourage students and farmers to learn from the school poultry project. Students learnt how to manage poultry and transferred the knowledge to their homes. Through this strategy, many farmers started to use the information after seeing the benefits of using the information at the school poultry project.

These findings (Table 4) indicate that most information providers disseminated information to the rural communities without strategies for ensuring that farmers utilise the information. The findings demonstrate further that face-toface communication was the main method used by information providers to make follow-ups on the utilisation of information in the surveyed rural communities. Taking the school poultry project as an example of a successful strategy, it is evident that poultry farmers were ignorant about the benefits of utilising such information. They utilised the knowledge after becoming aware of the benefits of utilising information on best farming practices. Therefore, there is a need for information providers to educate farmers on the benefits of utilising information on farming practices.

TABLE 4: Strategies used by information providers to ensure information is utilised $(N=22)$.

\begin{tabular}{lcc}
\hline Strategies & Frequency $(\boldsymbol{N})$ & $\mathbf{\%}$ \\
\hline Following up the farmers & 5 & 22.7 \\
Practising together with farmers & 4 & 18.2 \\
Demonstrating during the seminars & 4 & 18.2 \\
Requesting for feedback from farmers & 3 & 13.6 \\
School poultry project & 1 & 4.5 \\
\hline
\end{tabular}

Note: Multiple responses were possible. 


\section{Factors that hinder the use of poultry management information}

More than half of the surveyed farmers (228, 63.3\%) responded to the question on factors that hindered the use of poultry management information. The majority of the respondents indicated that limited assistance from experts and lack of skills on how to use the information were the main barriers. Other factors were limited literacy levels, unreliable information, low economic status, and lack of cooperation among farmers. Figure 2 shows the findings on factors that hinder the use of poultry management information.

Data from FGDs confirmed that the unavailability of assistance from experts such as extension officers was a major factor which limited farmers from using poultry management information. Other factors that hindered farmers from using poultry management information in descending order of importance were: lack of cooperation among poultry farmers, unreliability of the information, poor economic status, high cost of implementing the information and unavailability of poultry treatment drugs in the community. Some of the typical responses were:

'They only give us information, but we don't know how to use it. For instance, I read a poster on vaccination of poultry against Newcastle disease. I buy the drug, vaccinate the poultry, and they die. They should demonstrate to us how to do it, when to do it, and how often we should do it.

'There is a long distance from our community to the drug store. It is a day trip which requires funds for transport. Even if I get information, it is difficult to use it, because there is no drug store in our community, and I cannot afford the transport cost to town.'

The barriers identified in this study are similar to the obstacles reported by Odini (2014). Odini (2014) found that illiteracy, ignorance, poverty, inaccessibility of information and unreliable information were among the main barriers to female farmers' use of information in Kenya. The findings demonstrate that the factors hindering the use of poultry management information mainly originate from illiteracy

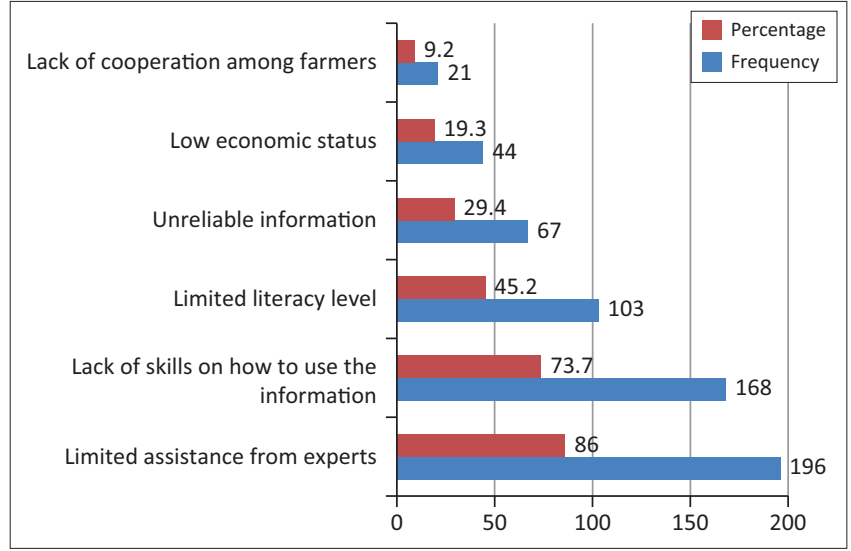

Note: Multiple responses were possible.

FIGURE 2: Factors that hinder the use of poultry management information $(N=228)$. and poverty among the rural farmers. Similar observations were made by Opara (2010), who asserted that low literacy and high poverty levels of farmers could affect their access to and use of agricultural information. Likewise, Dorsch (2000) reported that cost of information, lack of skills and geographical isolation were among the major hindrances to information use. Mtega (2012) also stressed that literacy levels of information seekers limit the utilisation of information.

The findings also indicate that farmers needed assistance from experts to use information, and they lacked skills on how to use the information. Accessed information can be effectively used by farmers if they know how to use it. Meyer (2005) emphasised that receivers of information must know how to use the information, otherwise the information will be useless. Mtega (2012) highlighted the fact that information can only be useful when effectively interpreted by the receivers. The implication is that farmers lack knowledge on how to use the accessed information. This situation is exacerbated by the fact that most of the farmers have low literacy levels, as reported in previous sections. Limited literacy level was one of the most cited barriers to information use.

The findings from interviews with information providers indicated that the low literacy level of farmers was the main barrier to information use. This indicates that farmers need knowledge to enable their effective utilisation of information. Imparting the needed knowledge to farmers can be achieved through seminars, training and demonstration. Thus, information providers need to consider having more seminars, training courses and demonstrations to increase farmers' skills on how to use the information that they receive. This is supported by Opara (2010), who emphasised that education gives an individual the ability to seek and use information.

The need for training and demonstration was also highlighted by some of the farmers in the surveyed communities, as clarified in the typical responses from the FGDs. One of the farmers stated that:

'They only give us information, but we don't know how to use it.'

Thus, training of farmers is an important issue to be considered for the effective utilisation of poultry management information in the surveyed communities. Farmers indicated limited assistance from experts and lack of skills as their major hindrance for information utilisation. In this case, the extension officers are the main experts in rural areas; hence they have a responsibility of shaping the future of information utilisation for increased poultry production. This implies that the extension officers have to put more effort into training farmers to utilise the information they acquire.

Furthermore, the study findings indicate that poverty among the rural population had a great influence on the way in which farmers utilised poultry management information. 
The findings revealed that poor economic status and the high cost of employing the suggested farming practices were among the most cited barriers to information use. This is an indication that poverty has an effect on information use. Similarly, Opara (2010) cited poverty as one of the main variables hindering information use. Daudu, Chado and Igbashal (2009) reported that financial difficulty was the major constraint to farmers' use of information in Benue State, Nigeria.

Thus, there is a need to find ways to make information services and agricultural inputs more affordable to rural farmers. This can be achieved through government subsidisation of agricultural inputs and all information products distributed to the rural areas. Availability of farming inputs such as poultry vaccines at a subsidised price could enhance the use of poultry management information in the surveyed rural communities. However, eradicating poverty in rural areas is the only permanent solution.

\section{Conclusion}

The findings suggest that farmers tended to use information that had direct impact on their farming activities. The high use of information on poultry disease control and poultry protection explains the need to ensure poultry are healthy and protected, while markets bring monetary gains. The low use of information on poultry production and hatching spells out lack of knowledge on the benefits of utilising such information. This implies that farmers use information they perceive as important to their farming activities. The study concludes that farmers were ignorant on the importance of utilising information, and information providers inadequately supported them. The situation calls attention to the government and other institutions responsible for information provision to facilitate information utilisation by ensuring that farmers are well informed. Based on the findings, information utilisation seemed to be determined by various factors, including inadequate knowledge and economic resources. It is therefore important to educate farmers by providing seminars and demonstrations using participatory approaches. It would also be important to adjust the planning for information dissemination by taking into consideration the factors that influence information utilisation.

\section{Recommendations}

- Information providers should conduct regular training on how to use the information, and have follow-up strategies to ensure that farmers are able to utilise the information.

- Information providers should devise better strategies for informing farmers on the benefits of information utilisation, such as farmers' field schools.

- Although oral communication seems to be popular in rural areas, the study recommends use of a variety of sources to complement each other. For instance, the use of print media to supplement oral messages communicated during the meeting or demonstration. It is also recommended that information be delivered in a variety of formats to accommodate various education categories of farmers.

- The government should subsidise the resources which are needed for effective functioning of the information system in rural areas.

- Capacity building should be the priority of the government, local authorities and other responsible institutions. This should involve providing training for farmers as well as the information providers. The training programmes for farmers should be geared towards imparting knowledge and skills for accessing and using information. The training programmes for information providers should focus on improving and updating their information provision skills. These programmes should be continuous to strengthen and update the knowledge base of both farmers and information providers in rural areas.

\section{Acknowledgements Competing interests}

The authors declare that they have no financial or personal relationships which may have inappropriately influenced them in writing this article.

\section{Authors' contributions}

P.N. was the project leader and assisted in the conceptualisation and execution of the project including dealing with correspondence from the editorial board. G.M. was responsible for data collection, analysis and drawing conclusion from the data. This was part of the project that formed the PhD study of G.M.

\section{References}

Bachhav, N.B., 2012, 'Information needs of the rural farmers: A study from Maharashtra, India: A survey', Library Philosophy and Practice, Paper 866, viewed 20 July 2013, from http://digitalcommons.unl.edu/libphilprac/866

Bartlett, J.C. \& Toms, E.G., 2005, 'How is information used? Applying task analysis to understanding information use', in CAIS Conference Proceedings: Data, information and knowledge in a networked world, viewed 12 June 2011, from http://www.cais-csi.ca/proceedings/2005/bartlett_2005.pdf

Boki, J.K., 2000, 'Poultry industry in Tanzania with emphasis on small-scale rural poultry. smallholder poultry project eastern and southern Africa', Journal of International Development 14(2), 23-35.

Byamugisha, H.M., Ikoja-Odongo, R. \& Nasinyama, G.W., 2010, 'Information needs and use among urban farmers in Kampala City in Uganda', Library and Information Research 34(108), 18-32.

Coudel, E. \& Tonneau, P., 2010, 'How can information contribute to innovative learning processes? Insight from a farmer university in Brazil', Agricultural Information Worldwide 3(2), 56-63.

Daudu, S., Chado, S.S. \& Igbashal, A.A., 2009, 'Agricultural information sources utilized by farmers in Benue State, Nigeria', Publication Agriculture and Technology 5(1), 39-48.

Dorsch, J.L., 2000, 'Information needs of rural health professionals: A review of the literature', Bulletin of the Medical Library Association 88(4), 346-354, viewed 15 September 2013, from http://www.ncbi.nlm.nih.gov/pmc/articles/PMC35256/ pdf/i0025-7338-088-04-0346.pdf

Eze, C.C., Ibekwe, U.C., Onoh, P.O. \& Nwajiuba, C.U., 2006, 'Determinants of adoption of improved cassava production technologies among farmers in Enugu State of Nigeria', Global Approaches to Extension Practice 2(1), 37-44.

Fawole, O.P., 2006, 'Poultry farmers' utilization of information in Lagelu local government area, Oyo State of Nigeria', International Journal of Poultry Science 5(5), 499-501. https://doi.org/10.3923/ijps.2006.499.501 
Food and Agriculture Organisation (FAO), 2011, Animal Husbandry and Animal Health Division- Poultry Sector Country Review for Tanzania, FAO, Rome.

Guèye, E.F., 2000, 'The role of family poultry in poverty alleviation, food security and the promotion of gender equality in rural Africa', Outlook on Agriculture 29(2) 129-136. https://doi.org/10.5367/000000000101293130

Heeks, R., 2005, 'Foundations of ICTs in development: The information chain', eDevelopment Briefing 3, 1-2.

Kalusopa, T., 2005, 'The challenges of utilizing information communication technologies (ICTs) for the small-scale farmers in Zambia', Library Hi Tech 23(3), 414-424. https:// doi.org/10.1108/07378830510621810

Kamba, M.A., 2009, Access to information: The dilemma for rural community development in Africa, viewed 2 June 2014, from https://smartech.gatech.edu/ jspui/bitstream/1853/36694/1/1238296264_MA.pdf

Knueppel, D., Cardona, C., Msofffe, G.E.P., Demment, M. \& Kaiser, L., 2010, 'Impact of vaccination against chicken Newcastle disease on food intake and food security in rural households in Tanzania', Food and Nutrition Bulletin 31(3), 436-445. https:// doi.org/10.1177/156482651003100306

Knueppel, D., Coppolillo, P., Msago, O.A., Msoffe, P.L., Mutekanga, D. \& Cardona, C., 2009, Improving Poultry Production for Sustainability in the Ruaha Landscape, Tanzania, viewed 5 June 2014, from http://files.figshare.com/483963/CaseStudy ImprovingPoultryProduction_Tanzania.pdf

Leedy, P.D. \& Ormrod, J.E., 2005, Practical research: Planning and design, 8th edn., Pearson Education, Upper Saddle Rive, NJ.

Lwoga, E.T., Stilwell, C. \& Ngulube, P., 2011, 'Access and use of agricultural information and knowledge in Tanzania', Library review 60(5), 383-395. https://doi.org/ 10.1108/00242531111135263

McNeil, P. \& Chapman, S., 2005, Research methods, 3rd edn., Routledge, New York.

Meho, L.I. \& Hass, S.W., 2001, 'Information seeking behaviour and use of social science faculty studying stateless nations: A case study', Library and Information Science Research 23(1), 5-25. https://doi.org/10.1016/S0740-8188(00)00065-7

Meyer, H.W.J., 2005, 'The nature of information and effective use of information in rural development', Information Research, 10(2), paper 214, viewed 29 Novembe 2016, from http://InformationR.net/ir/10-2/paper214.html

Minga, U.M., Yongolo, M.G.S., Mtambo, M.M.A., Mutayoba, S.K., Lawrence, P., Mwalusanya, N.A. et al., 2000, 'The potential for rural poultry production and health in Africa', in G. Pedersen, A. Permin, \& U. Minga (eds.), Proceeding of the workshop on the possibilities for smallholder poultry projects in Eastern and Southern Africa, pp. 83-94, The Royal Veterinary and Agricultural University, Copenhagen, Denmark.

Msoffe G.E.P., 2015, Access and use of poultry management information in selected rural areas of Tanzania, University of South Africa, viewed 29 November 2016 from http://uir.unisa.ac.za/handle/10500/19021
Mtega, W.P., 2012, 'Access to and usage of information among rural communities: A case study of Kilosa District Morogoro Region in Tanzania', Partnership: The Canadian Journal of Library and Information Practice and Research 7(1), viewed 29 November 2016, from https://journal.lib.uoguelph.ca/index.php/perj/article/ view/1646/2462\#.WD2cRfl95Q

Ngulube, P., 2015, 'Qualitative data analysis and interpretation: Systematic search for meaning', in E.R, Mathipa \& M.T. Gumbo (eds.), Addressing research challenges: making headway for developing researchers, pp. 131-156. Mosala-MASEDI Publishers \& Booksellers cc, Noordywk, South Africa.

Odini, S., 2014, 'Access to and use of agricultural information by small scale women farmers in support of efforts to attain food security in Vihiga County, Kenya', Journal of Emerging Trends in Economics and Management Sciences 5(2), Kenya', Journ.

Ofuoku, A.U., Emah, G.N. \& Itedjere, B.E., 2008, 'Information utilization among rural fish farmers in Central Agricultural Zone of Delta State, Nigeria', World Journal of Agricultural Sciences 4(5), 558-564.

Olaniyi, O.A. \& Adewale, J.G., 2011, 'Nigerian Rural Youths' utilisation of agricultural information on selected arable crops: An empirical evidence', Agricultural Information Worldwide 4, 81-87.

Olaniyi, O.A. \& Adewale, J.G., 2012, 'Assessment of utilization of agricultural information on maize production among rural youth: Panacea for sustainable food security in Nigeria', OIDA International Journal of Sustainable Development $5(2), 75-86$

Opara, U.N., 2010, 'Personal and socio-economic determinants of agricultural information use by farmers in the Agricultural Development Programme (ADP) zones of Imo State, Nigeria', Library Philosophy and Practice, Paper 434, viewed 15 August 2013, from http://digitalcommons.unl.edu/ libphilprac/434

Potnis, D.D., 2014, 'Beyond access to information: Understanding the use of information by poor female mobile users in rural India', The Information Society 31(1), 83-93. https://doi.org/10.1080/01972243.2014.976687

Temba, B.A., Kajuna, F.K., Pango, G.S. \& Benard, R., 2016, 'Accessibility and use of information and communication tools among farmers for improving chicken production in Morogoro municipality, Tanzania', Livestock Research for Rural Development 28, viewed 28 November 2016, from http://Irrd.cipav.org.co/ Irrd28/1/temb28011.html

United Republic of Tanzania (URT), 2006, National livestock policy, viewed 10 September 2011, from http://www.mifugo.go.tz/documents_storage/ ILivetockPolicy.pdf

Waller, B.E., Hoya, C.W., Hendersonb, J.L., Stinnera, B. \& Welty, C., 1998, 'Matching innovations with potential users, a case study of potato IPM practices', Agriculture, Ecosystems \& Environment 70(2), 203-215. https://doi.org/10.1016/S01678809(98)00149-2 